RELACult - Revista Latino-Americana de Estudos em Cultura e Sociedade

\title{
Estudos da paisagem e elaboração de roteiros turísticos
}

\author{
Estudios del paisaje y elaboración de itinerarios turísticos \\ Landscape studies and elaboration of tourist routes
}

\section{Marcina Amália Nunes Moreira ${ }^{1}$}

\begin{abstract}
Resumo
Esta comunicação tem como objetivo propor a leitura da paisagem, tomando-se por base seu caráter linguístico, com vistas a uma possível versão metodológica de apoio à elaboração de roteiros turísticos. A paisagem representa uma categoria de análise da Geografia. Contudo, inexiste uma ciência que contemple, atualmente, o estudo da paisagem em sua totalidade devido à complexidade de suas abordagens. $\mathrm{O}$ artigo fundamenta-se, portanto, na interpretação da paisagem, possibilitando a elaboração de roteiros que envolvam não somente o olhar, mas os demais sentidos humanos, como uma forma de interação e adequação à política pública de turismo em âmbito nacional.
\end{abstract}

Palavras-chave: Turismo. Paisagem. Roteiros Turísticos.

\section{Resúmen}

Esta comunicación tiene por objeto proponer la lectura del paisaje, tomando como base su carácter linguístico, con miras a una posible versión metodológica para apoyar el desarrollo de itinerarios turísticos. El paisaje es una categoría de análisis de Geografía. Sin embargo, no existe una ciencia que se ocupa actualmente el estudio del paisaje en su totalidad debido a la complejidad de sus enfoques. El artículo se basa, por lo tanto, sobre la interpretación del paisaje, permitiendo el desarrollo de secuencias de comandos que implican no sólo la apariencia, pero otros sentidos humanos, como una forma de interacción y adaptación a la política turística pública en todo el país.

Palabras-clave: Turismo. Paisaje. Itinerarios turísticos.

\section{Abstract}

This communication aims to propose the reading of the landscape, based on its linguistic character, with a view to a possible methodological version to support the elaboration of tourist itineraries. The landscape represents a category of analysis of Geography. However, there is no science that presently contemplates the study of landscape in its entirety due to the complexity of its approaches. The article is based, therefore, on the interpretation of the landscape, allowing the elaboration of itineraries that involve not only the look, but the other human senses, as a form of interaction and adequacy to the national tourism public policy.

Keywords: Tourism. Landscape. Tourist routes.

\section{Introdução e generalidades da comunicação}

O presente artigo tem como objetivo propor a leitura da paisagem, tomando-se por base seu caráter linguístico. Esta abordagem revela uma possível versão metodológica de apoio à

\footnotetext{
${ }^{1}$ Turismóloga, Mestre em Geografia e Doutoranda no Programa Interdisciplinar em Estudos do Lazer, pela UFMG. É docente efetiva do quadro de professores do Instituto de Ciências Humanas da Universidade Federal de Viçosa, campus Florestal, MG. E-mail: marcinanunes@hotmail.com.
} 
elaboração de roteiros turísticos que podem ser inseridas às propostas do Ministério do Turismo, bem como anteriormente tratado em dissertação de Mestrado no Programa de pós-graduação em Geografia da UFMG, intitulada "Turismo e interpretação da paisagem em fazendas, caminhos e aglomerados rurais: roteiros de Alto Rio Doce, MG”.

Uma política pública de turismo pode ser entendida como um conjunto de intenções, diretrizes e estratégias e/ou ações deliberadas, no âmbito do poder público, em virtude do objetivo geral de alcançar e/ou dar continuidade ao pleno desenvolvimento da atividade turística num dado território (CRUZ, 2000a). Assim, torna-se crucial a contextualização do turismo enquanto política pública, para entender o processo de planejamento desta atividade no país.

Ao se resgatar o planejamento público do turismo no Brasil em, basicamente, dois momentos, verifica-se que um primeiro período, que abrange a criação da Embratur em 1966, durante o regime militar, esgota-se em fins da década de 90. Até então, foram notórios os investimentos em infraestrutura hoteleira, principalmente, no Nordeste brasileiro, enquanto fomento ao receptivo turístico no país.

Um segundo período remete aos últimos anos da década de 90 e início do século XXI, passando pelo contexto de criação do Ministério do Turismo. Um dos principais programas efetivados no período foi o Programa Nacional de Municipalização do Turismo, diferenciado por uma nova metodologia de planejamento com enfoque participativo. Foi relevante no quesito estímulo ao desenvolvimento turístico nacional partindo da descentralização de políticas públicas de turismo e do fortalecimento do planejamento turístico nos municípios.

Assim, ao mesmo tempo em que o PNMT deu entendimento social à atividade turística nos municípios o mesmo projetou a importância do envolvimento das lideranças nas diversas fases de seu planejamento. Em um momento em que pouco se discutia sobre o turismo no Brasil, o dito plano não conteve sua importância meramente econômica para os municípios. Entretanto Cruz (2000b) esclareceu que o programa, além de frágil, expôs dúvidas em relação ao processo de participação da comunidade e as carências em função da exclusão de alguns métodos de avaliação das potencialidades de cada município, como é o caso do inventário de oferta turística. $^{2}$

A preocupação por incorporar novas abordagens que ampliassem as dimensões do turismo aos problemas de ordenação do território justificou a necessidade de analisar e

\footnotetext{
${ }^{2}$ O Inventário da Oferta Turística pode ser entendido como o resultado do levantamento, da identificação e do registro dos atrativos, dos serviços e dos equipamentos turísticos e da infraestrutura de apoio ao segmento. Tem a finalidade de servir como instrumento solidificador das informações para fins de planejamento e gestão da atividade turística (MTUR 2009).
} 
classificar uma série de fatores que contribuíram à explicação dos processos para o planejamento do território turístico. Tornou-se relevante uma visão aplicada aos componentes que influenciavam as formas de aproveitamento turístico, no marco de uma racionalização e de uma gestão eficiente dos recursos turísticos.

O papel que o turismo tem na educação e formação cultural de uma sociedade é relevante no que diz respeito ao desenvolvimento sustentável desta atividade, tendo em vista a valorização e proteção do patrimônio natural e cultural de cada região, além do respeito à sua própria diversidade. Contudo, não basta a existência de recursos naturais e culturais em determinadas regiões, territórios ou lugares. Torna-se necessária a incorporação de ações que agreguem valor à atratividade desses recursos de modo a torná-los turísticos.

Uma principal característica norteadora das Políticas Nacionais de Turismo no período que compreende a década de 60 até o final da década de 90 no Brasil abrange certa visão economicista dessa atividade. Tal característica é notável em grande parte da literatura produzida por especialistas e também por órgãos públicos. Ou seja, o turismo enquanto atividade puramente geradora de divisas contribuiu também e principalmente nesse período ao empobrecimento de seu discurso epistemológico e acadêmico.

Por fim, é característica do início deste século em termos de diretrizes públicas a diversificação da oferta de atrativos turísticos e dos incentivos ao aumento do tempo de permanência do turista no país. Assim, uma das formas de sustentação desta atividade enquanto prática acadêmica e campo de estudos sociais são orientar a elaboração de roteiros que levem em consideração os aspectos motivacionais e socioculturais tanto dos anfitriões quanto dos forasteiros. Para tanto, a seguir, será apresentada uma abordagem geográfica da temática paisagem que vem contribuindo à elaboração de roteiros turísticos locais e regionais, partindose de um viés ontológico.

\section{Revisão de Literatura}

O processo de investigação do conceito de paisagem foi influenciado por transformações profundas no imaginário social em cada período e contexto histórico. A investigação desse conceito passa pela representação do espaço, ou seja, o estudo da paisagem enquanto expressão da arte. Na Grécia Antiga, a arte foi sinônima da representação da forma e do conteúdo, além de significar a mediação da relação homem/meio. Sobremaneira, a paisagem também foi retratada enquanto arte.

Alexandre Von Humboldt (1769-1859), cientista naturalista e um dos fundadores da geografia científica, aprofundou o sentido do termo paisagem a partir da observação da natureza 
RELACult - Revista Latino-Americana de Estudos em Cultura e Sociedade

Revista Latinoamericana de Estudios en Cultura y Sociedad | Latin American Journal of Studies in Culture and Society

V. 03, nº 02 , mai-ago., 2017, p. 44-52 | relacult.claec.org e-ISSN 2016/Atual: 2525-7870 | e-ISSN 2015/2016: 2447-018X

e das sensações que tinha através disso. Não foi objetivo de o naturalista sistematizar um novo conceito de paisagem, mas sua contribuição no entendimento do mesmo enquanto importante contemplação pelos homens foi inquestionável. Dessa maneira, considera-se que Humboldt foi um dos primeiros a dar à paisagem um aspecto ontológico (PASSOS, 2003).

Foi somente nas últimas décadas do século XIX, que a paisagem ganhou significado científico com o surgimento da escola de geografia alemã, que passou a estudá-la enquanto estatuto científico e objetivo. O geógrafo Carl O. Sauer observou, no início do século XX, que o estudo da paisagem iniciado pelos alemães não poderia focalizar apenas o meio físico e excluir o homem que também fazia parte deste contexto e trouxe o entendimento da essência do espaço a partir do homem.

Para Sauer a paisagem deveria ser dividida em natural e cultural. As áreas naturais seriam aquelas em que o homem nunca teria agido sobre as mesmas, ou seja, não houve interferência humana. Por mais que isso possa aguçar o pensamento de alguns, essa tipologia encontra-se contraditória atualmente. As áreas culturais, por outro lado, seriam as naturais que sofreram interferências da ação humana, basicamente.

Para este autor, paisagem representaria uma unidade dentro do diverso, uma categoriasíntese de análise do espaço, resultado da ação humana em uma área, através de intervenções ou por outras formas de cultura. Naquele contexto, percebeu-se que o estudo da paisagem em geografia seria possível a partir da intervenção humana na natureza, pois como ressalta Sauer (1998), os usos dados a determinados espaços, através das ações humanas sob o arcabouço morfológico geram formas que compõem novas versões da paisagem. (SAUER, 1998).

Corrêa e Rosendahl (1998:9) interpretam a teoria de Sauer, abordando que a "paisagem geográfica é vista como um conjunto de formas naturais e culturais associadas em uma dada área e analisadas morfologicamente, vendo-se a integração das formas entre si e o caráter orgânico ou quase orgânico delas. O tempo é uma variável fundamental. A paisagem cultural ou geográfica resulta da ação, ao longo do tempo, da cultura sobre a paisagem natural". Percebese com esta afirmação que a paisagem é relevante às práticas turísticas pelo fato de envolver os aspectos naturais, que dizem respeito ao relevo, às formações vegetais, dentre outras, e culturais, que remetem à história dos lugares, às tradições e outros aspectos interligados à motivação das viagens individuais ou em grupos.

Seguindo essa abordagem, porém, trazendo novas significações para esse conceito, Claval (2002) colabora à construção de um significado de paisagem enquanto representação cultural. Segundo o autor, a dinâmica cultural deve ser considerada ao se analisar diferentes concepções de espaço na contemporaneidade, bem como as influências que o conformam. 
(CLAVAL, 2002). O autor inova o conceito de paisagem cultural, portanto, no sentido de que a mesma não é humanizada somente pela ação do homem, mas também pelo seu pensamento.

A paisagem representa uma categoria de análise da Geografia. Contudo, inexiste uma geografia hoje que contemple o estudo da paisagem em sua totalidade devido à complexidade de suas abordagens. Cada vez mais suas curiosidades vêm sendo apropriadas pelas ciências que tratam dos estudos perceptivos, sensitivos e afetivos pelo fato de a paisagem possuir valores subjetivos relacionados à cultura.

Nesse sentido, pode-se dizer que a própria vida em sociedade é mediada pela linguagem, sendo que a comunicação é permitida não somente pela fala, mas pela produção de formas, movimentos e leituras. Portanto, a referência à linguagem, neste artigo, trata de uma gama incrivelmente intrincada de formas sociais de comunicação e de significação que inclui a linguagem verbal articulada, mas absorve também, inclusive, a linguagem dos surdos-mudos, o sistema codificado da moda, da culinária e tantos outros. (SANTAELLA, 1988).

No estudo semiótico, qualquer estímulo emitido pelos objetos do espaço é denominado sinal e, assim, é operado pelo homem e para o homem, enquanto produto de sua consciência. Esses sinais são emitidos enquanto signos e entendidos como um tipo de linguagem. Percebemse diversos tipos de signos constituídos numa zona rural, por exemplo, nos cultivos agrícolas, pastagens, pomares e caminhos que contribuem ao entendimento das funções de cada objeto distribuído espacialmente em uma dada área.

Qualquer atividade humana, bem como as atividades turísticas, são dotadas de sentido. São, portanto, significantes. Partindo-se daí, há de se considerar, então, uma paisagem visível ou material, representante de um conjunto de significantes possíveis, passível de diferentes interpretações ou "olhares", que caracterizam seu (s) significado (s). Cada signo, consequentemente, declara seu próprio significado podendo possuir diversos significantes a partir dos sentidos de cada diferente observador/turista.

Assim, a ação de produzir e interpretar signos na paisagem é cotidiana e é experimentada por todo ser humano ao longo da vida. Uma gama de significados diversos para uma mesma paisagem advém da própria maneira de pensar das pessoas, conivente com sua formação cultural e educacional. E são a partir dessas considerações que serão reveladas algumas interpretações de paisagens enquanto recursos metodológicos essenciais para a elaboração de roteiros turísticos, especialmente de base local/regional.

\section{Apontamentos e discussões preliminares}


A paisagem existe através dos olhos de quem a vê. A feição da paisagem lida ou interpretada é influenciada pelas sensibilidades individuais e coletivas. Estas sensibilidades se modificam conforme as filiações, ou seja, o sentido de pertencimento cultural e territorial. $\mathrm{O}$ valor dado à paisagem varia de acordo com a opinião pessoal do observador, variando conforme sua própria relação com o meio. Isto é, se o observador é um agricultor, comerciante, industrial, residente, veranista ou turista, por exemplo, obterá diferentes focos de apreensão interpretativa da paisagem.

O turismo promove in situ o significado do legado cultural, instigando curiosidades e exaltando as emoções do visitante através de seus sentidos. Para Murta e Goodey (2002: 4), "nada substitui, no entanto, a interpretação ao vivo, quando realizada por guias condutores sensíveis ao ambiente e às necessidades dos visitantes”. Entender o território e seu modo de ocupação também influencia na observação da paisagem de determinado lugar. Assim, concluise que existem tantas percepções das paisagens quanto observadores e usuários das mesmas.

Diferentes abordagens sobre paisagem apontam para a compreensão de que ela se constitui como a porção visível do espaço geográfico (SANTOS, 1996), sendo então a primeira instância de contato do viajante com seu destino além de estar no centro do eixo de atratividades daquele espaço. Seu estudo constitui-se, assim, como um dos elementos mais importantes da atratividade nos espaços turísticos, pois um não se desvincula do outro, sendo diretamente relacionados entre si.

Assim, paisagem não deve ser tomada como categoria desvinculada do espaço, uma vez que é frequentemente reelaborada em detrimento aos fatores específicos que remetem, por exemplo, à economia e aos padrões culturais das sociedades aliados aos fatores geográficos que possuem relevante papel na prestação dos serviços turísticos. (YÁZIGI, 2002).

As diversas vertentes da atividade turística se dão devido às preferências das pessoas por paisagens diversificadas. Estas, por sua vez, estão relacionadas às motivações de viagem do turista. As paisagens turísticas existem a partir da existência de sociedades que, ao longo do arcabouço natural, constroem e reconstroem outras paisagens, aquelas denominadas culturais, políticas, sociais, econômicas, etc.

Os turistas movem-se através de cenários e, muitas vezes, os mesmos complementam ou representam integralmente sua principal motivação para viajar. Por outro lado, o turismo é considerado elemento essencial à proteção da memória e identidade, sendo relevante a leitura da paisagem em sua dimensão estética e cultural para o estabelecimento da oferta turística.

A viabilização da atividade turística enquanto prática social e espacial, considerada sua dimensão histórico-cultural, a partir da interpretação da paisagem possibilita uma adequada 
orientação das atividades humanas no território. Por isso analisar a paisagem é importante e contribui enquanto instrumento de adequação ao planejamento turístico do território.

Os processos sociais demarcam, assim, formas, funções e significados sociais no espaço e o turismo é um desses processos. A paisagem sugere o reflexo da sociedade que a (re) produz sob a relação sociedade, espaço e natureza, sendo a presença humana e a incorporação de subjetividades, condições essenciais de sua existência.

Caracteriza-se, desta forma, o conceito de paisagem que inclui aspectos físicos e humanos num contexto de estudos do Turismo, desvinculando-se a ideia de imagem, que remete somente à forma, excluindo-se as percepções e vivências do turista. Assim, para cada observador/turista, a paisagem tem um sentido, seja de contemplação, utilitarista ou estética.

A visão de espaço e o conceito de paisagem estão diretamente relacionados ao desenvolvimento da atividade turística, pois o turismo apropria-se do espaço, consumindo o mesmo e estabelecendo relações de consumo, seja de cultura, mercadoria, conhecimentos, tradições entre visitante e visitado. Portanto, a interpretação e compreensão da paisagem, enquanto categoria de análise do espaço turístico permite que a busca pelo inusitado que fundamenta o encontro seja carregada de valores e significados, através da leitura de diferentes cores, formas, texturas e linhas.

Entende-se o estudo da paisagem com foco na atividade turística como o resultado da interação do homem com o meio ambiente, no espaço geográfico. A leitura da realidade socioespacial através da paisagem exige uma abordagem integrada, no sentido de superar a dicotomia da sua natureza. Por essas razões é imprescindível transcender a observação e descrição superficial e buscar o entendimento da essência naquilo que se vê ou se sente, através de nossos sentidos.

\section{Conclusão}

A paisagem, enquanto recurso educacional e de desenvolvimento turístico, é alvo de pesquisas no Brasil desde meados dos anos 90 do século passado. Seu estudo relaciona-se à formação de uma identidade coletiva e ao patrimônio de uma localidade. Se, de alguma maneira, sua interpretação valoriza a experiência do visitante em um lugar, de outra, a própria paisagem é valorizada e incorporada ao patrimônio enquanto atração turística. Seja a paisagem vista sob um viés cultural ou não, ela é o próprio patrimônio.

Dessa forma, cada vez mais a interpretação baseada em leituras de paisagem tem ganhado destaque metodológico nas publicações acerca de diversas áreas do conhecimento por englobar, de antemão, uma característica mediadora do próprio ato de se comunicar, ou seja, a 
paisagem em sua função de linguagem. Partindo desses pressupostos, uma das formas de se interpretar o patrimônio local implica no processo de acrescentar valor à experiência do visitante, por meio do fornecimento de informações e representações que realcem a história e as características culturais e ambientais de um lugar.

Igualmente a outros processos de produção da linguagem, a interpretação também pode utilizar-se de vários instrumentos facilitadores que realcem a informação do lugar que se quer transmitir. No turismo esses instrumentos normalmente são reduzidos a fotografias e desenhos que correspondem a imagens de apresentação do lugar e de expressões culturais do mesmo, através dos roteiros turísticos.

A interpretação da paisagem com vistas ao planejamento do turismo é instrumento de comunicação entre o morador e o visitante. É imprescindível que se considere, assim, a importância do envolvimento da comunidade local no processo de roteirização numa abordagem que envolva temas do passado, presente e futuro, destacando-se as diversidades e pluralidades culturais.

A tendência à descentralização das políticas referentes ao planejamento do turismo no Brasil apresenta um contexto favorável ao fomento desta atividade em diversas escalas. Neste aspecto, há uma ampliação da participação e inclusão social, ambiental, cultural e política de alguns municípios menores, carentes em infraestrutura básica, porém vantajosos em termos de recursos que podem ser explorados de maneira sustentável na atividade turística.

A roteirização turística proposta pelo MTUR conta com ações que envolvem a sensibilização e integração de cada ator local, a pesquisa do perfil da demanda, a análise dos possíveis impactos positivos e negativos, a qualificação dos serviços turísticos e a promoção dos mesmos. Contudo, adaptar a interpretação da paisagem em campo a tal metodologia sustenta um olhar aproximado inconcebível no processo adotado pelo governo.

A elaboração visual do território partindo das imagens de satélite e dos trabalhos de campo regados a diálogos com as comunidades são instrumentos imprescindíveis à caracterização de uma paisagem com vistas à elaboração de roteiros turísticos. Numa abordagem polissêmica, tratar desses instrumentos, em conjunto, permite abordar se realmente um está em conformidade com o outro, retratando estilos de vida, atividades cotidianas, cultura e história local.

Com isso, a operacionalização de roteiros turísticos em um município com baixo Índice de Desenvolvimento Humano (IDH), por exemplo, pode apresentar um produto competitivo, fortalecendo o turismo interno e dando ao próprio brasileiro os benefícios desta atividade. Através das práticas turísticas sustentadas na interpretação da paisagem e com a participação e 

e-ISSN 2016/Atual: 2525-7870 | e-ISSN 2015/2016: 2447-018X

apoio das comunidades locais, o fluxo de visitantes pode ser orientado à preservação e proteção daquela paisagem.

\section{Referências}

BRASIL. Ministério do Turismo. Plano Nacional do Turismo 2003/2007: Diretrizes, Metas e Programas. Ministério do Turismo. Brasília, 2003.

BRASIL. Ministério do Turismo. Plano Nacional do Turismo 2007/2010: Uma viagem de Inclusão. Ministério do Turismo. Brasília, 2007.

CLAVAL, P. A revolução pós-funcionalista e as concepções atuais da Geografia. In: MENDONÇA, F.; KOZEL, S. (Orgs.). Elementos de epistemologia da Geografia Contemporânea. Curitiba: UFPR, 2002.

CORRÊA, Roberto Lobato \& ROSENDAHL, Zeny (org.) Paisagem, tempo e cultura. UERJ: Rio de Janeiro, 1998.

CRUZ, Rita de Cássia. Introdução à geografia do turismo. São Paulo: Roca, 2000a.

CRUZ, Rita de Cássia. Política de turismo e território. São Paulo: Contexto, 2000b.

MURTA, S. M.; GOODEY, B. Interpretação do patrimônio para visitantes: um quadro conceitual. In: Interpretar o patrimônio - um exercício do olhar. Belo Horizonte: UFMG, 2002 .

PASSOS, M.M. dos. Biogeografia e Paisagem. Presidente Prudente: Edição do Autor, 2003.

SANTAELLA, Lúcia. O que é semiótica. São Paulo: Brasiliense, 1983.

SANTOS, Milton. A natureza do espaço: técnica e tempo, razão e emoção. São Paulo: Hucitec, 1996.

SAUER, Carl O. A morfologia da paisagem. In: CORRÊA; ROZENDAHL (orgs). Paisagem tempo e cultura. Rio de Janeiro: EDUERJ, 1998.

YÁZIGI, Eduardo. Turismo: espaço, paisagem e cultura. São Paulo: Hucitec, 2002, 3 ed. $241 \mathrm{p}$. 